\title{
LA PROTECCIÓN DEL MEDIO AMBIENTE SEGÚN EL SISTEMA INTERAMERICANO DE DERECHOS HUMANOS: SOCIOAMBIENTALISMO Y EL CASO BELO MONTE
}

\author{
Danielle AnNe Pamplona
}

Profesora titular de Derecho Público en la Pontificia Universidad Católica de Paraná (PUC-PR), Brasil

E-mail: danielle.pamplona@pucpr.br.

\section{DANIELLE ANNONI}

Profesora titular de Derecho Internacional Público y de Derechos Humanos en la Universidad Federal de Paraná (UFPR), Brasil

E-mail: danielle.annoni@ufpr.br

Recibido: 10 de junio de 2015 / Aceptado: 29 de febrero de 2016

RESUMEN: El objeto del presente trabajo es establecer la importancia del caso Belo Monte para el derecho brasileño así como para el sistema regional del cual Brasil forma parte. La investigación ha sido desarrollada mediante el análisis de documentos oficiales del Sistema Interamericano de Derechos Humanos y de fallos provenientes del Poder Judicial de Brasil. En el ámbito internacional, este trabajo establece una relación del caso Belo Monte con el fenómeno de la ambientalización (greening, en inglés) del derecho internacional. A continuación se explica el porqué de la importancia del caso Belo Monte. En relación con el derecho interno brasileño, la preocupación de las autoras se ha centrado en establecer la reivindicación de los derechos de los pueblos indígenas y ribereños de las orillas del río Xingú como marco del movimiento socioambiental, más allá de detallar las diferentes demandas judiciales de estos, basadas en el incumplimiento de las leyes y los acuerdos entre el Gobierno, la constructora y la población afectada. 
ABSTRACT: The objective of this study is to establish the relevance of the case Belo Monte to Brazilian law and the regional system to which Brazil is a member. The research was done in the inter-American system of human rights documents and in Brazilian courts decisions. Internationally, the text relates the case of Belo Monte with the greening phenomenon of international law. Second, it is made clear in the text what is the case Belo Monte, through the narrative of events. Regarding the internal law, the concern of the text was to establish the beginning of claims in favour of the rights of indigenous and riverside people as a landmark for the environmental movement, and indicates the various law suits developed on the basis of violation of legal commands and agreements.

RESUM: L'objecte del present treball és establir la importància del Cas Belo Monte per al Dret brasiler així com per al sistema regional del qual Brasil forma part. La recerca ha estat desenvolupada mitjançant l'anàlisi de documents oficials del Sistema Interamericà de Drets Humans i de decisions judicials provinents del Poder Judicial de Brasil. En l'àmbit internacional, aquest treball estableix una relació del Cas Belo Monte amb el fenomen de la ambientalització (greening, en anglès) del Dret internacional. A continuació, mitjançant la narrativa dels fets, s'aclareix, la importància del Cas Belo Monte. En relació al Dret intern brasiler, la preocupació de les autores ha residit a establir el moment de reivindicació dels drets dels pobles indígenes i riberencs que habiten a les ribes del riu Xingú com a marc del moviment socioambiental, més enllà d'indicar les diferents demandes judicials d'aquests, fetes en base a l'incompliment de les lleis i acords entre el govern, constructora i població afectada.

PALABRAS CLAVE: Socioambientalismo - Derechos humanos - Ambientalización - Caso Belo Monte.

KEYWORDS: Socio-environmentalism — Human Rights — Greening — Belo Monte Case. 
PARAULES CLAU: Socioambientalisme - Drets humans - Ambientalització - Cas Belo Monte.

Sumario: I. Introducción. II. La ambientalización del derecho internacional de los derechos humanos: el caso Yanomami como paradigma. III. La importancia para Brasil y el mundo de la lucha por el río Xingú: el socioambientalismo. IV. Para comprender el caso Belo Monte: desde Brasil hacia el Sistema Interamericano. V. Conclusiones. VI. Referencias bibliográficas.

\section{INTRODUCCIÓN}

La construcción de grandes obras de infraestructura es una situación que genera preocupaciones en los distintos campos de la ciencia. Siempre existirán cuestiones políticas que atañen a los intereses de los constructores, de la sociedad y de la población directamente afectada por tales obras. Dichos intereses suelen ser numerosos, pues a menudo estas grandes obras afectan a territorios extensos. Algunas cuestiones están relacionadas con el medio ambiente y los derechos humanos, mientras que otras afectan a toda la población nacional si se acepta el punto de vista según el cual la obra busca beneficiar a la nación mediante la generación de energía.

En Brasil, el caso Belo Monte es el ejemplo más reciente de violaciones de derechos humanos en beneficio del desarrollo, pero no es el único en las Américas. Hace años que consta en la agenda del Estado brasileño el reto de construir grandes obras de infraestructura, en especial en la región amazónica, cuyo potencial energético es inmenso. De modo que Belo Monte es el segundo capítulo de una historia triste y trágica a la vez, surgido al igual que el Sistema Interamericano en la década de 1980, y ha inaugurado un fenómeno internacional denominado en inglés greening del derecho internacional, y en especial del derecho internacional de los derechos humanos ${ }^{1}$.

El medio ambiente es, sin duda, un patrimonio que debe ser protegido, y los debates dirigidos a dar mayor eficacia internacional a la protección contra sus violaciones no son

\footnotetext{
${ }^{1}$ BERMANN, C., Brasil não precisa de Belo Monte, Amigos da Terra-Amazônia Brasileira, São Paulo, Brasil, 2002. Recuperado el 20 de febrero de 2015, de

$<$ http://www.amazonia.org.br/opiniao/artigo_detail.cfm?id=14820>.
} 
nada nuevo. Sin embargo, los instrumentos de protección internacional del medio ambiente, entre los cuales se puede citar el Convenio sobre la Diversidad Biológica, de 1992, y sus acuerdos, no han sido capaces de crear instrumentos jurídicos imperativos y vinculantes para los Estados, lo que hubiera satisfecho a los ambientalistas, a través de la creación de un Tribunal Internacional Ambiental basado en los modelos de protección de los derechos humanos ${ }^{2}$.

Con vistas a evitar que la impunidad recurrente perdurara, el Sistema Interamericano de Derechos Humanos ha pasado a analizar, por vía refleja, los casos de daño al medio ambiente, reconociendo tal derecho como un derecho humano a la vida, la salud y la propiedad. El caso que inaugura esta interpretación en el Sistema Interamericano es efectivamente un caso que involucra Brasil contra el pueblo indígena yanomami, episodio que también tiene como tela de fondo la región amazónica, lo que muestra que el caso Belo Monte es otro capítulo de una larga serie de violaciones históricas de los derechos y el hábitat de los pueblos indígenas y las poblaciones tradicionales amazónicas en beneficio de grupos económicos privados ${ }^{3}$.

Sin embargo, el caso Belo Monte es diferente del caso Yanomami ya que Brasil ha adoptado una posición distinta ante el Sistema Interamericano de Derechos Humanos, rompiendo su histórica postura de negociador. Ya han pasado treinta años desde el caso Yanomami y Brasil vuelve a despertar el interés de la comunidad internacional por el trato que da a los pueblos indígenas nacionales. En este sentido, el presente trabajo tiene como objetivo analizar, a partir del caso Yanomami y del caso Belo Monte, cómo el Sistema Interamericano de Derechos Humanos viene tratando la temática ambiental, consolidando la idea de que el daño al medio ambiente supone una violación de los derechos humanos ${ }^{4}$.

\footnotetext{
${ }^{2}$ MURPHY, S. D., "Does the world need a new international environmental court", Geo. Wash. J. Int'l L. \& Econ., v. 32, 1999, p. 333.

${ }^{3}$ FAINGUELERNT, M., "Belo Monte. Reflexiones críticas sobre la trayectoria histórica del proyecto de la hidroeléctrica y los escollos de las licencias ambientales en el Brasil", Revista Contrapunto. Bienes comunes. Saqueo y resistencias, Universidad de la República, Montevideo, junio de 2013, p. 42.

${ }^{4}$ CARVAlHO, A. S. C., et al., "Levels of $\mathrm{As}, \mathrm{Cd}, \mathrm{Pb}$ and $\mathrm{Hg}$ found in the hair from people living in Altamira, Pará, Brazil: environmental implications in the Belo Monte area", J. Braz. Chem. Soc., 2009, vol. 20, núm. 6, p. 18.
} 


\section{LA AMBIENTALIZACIÓN DEL DERECHO INTERNACIONAL DE LOS DERECHOS HUMANOS: EL CASO YANOMAMI COMO PARADIGMA}

Pese a que la Convención Americana sobre Derechos Humanos no se manifiesta sobre la protección ambiental en ninguno de sus artículos, su interpretación mediante la Comisión Interamericana de Derechos Humanos ampara la protección ambiental, especialmente relacionada con los pueblos indígenas, en un fenómeno conocido por la doctrina jurídica como greening, traducido en castellano como 'ambientalización' del derecho internacional.

Esta protección a la cual se hace referencia por vía refleja o de rebote, es decir, que interpreta la defensa del medio ambiente como un derecho humano fundamental, no es un fenómeno exclusivo del Sistema Interamericano de Derechos Humanos ${ }^{5}$. El caso Powell y Rayner contra el Reino Unido en la década de 1990 ante el Tribunal Europeo de Derechos Humanos demuestra que tanto el sistema europeo como el interamericano prestan especial atención a las violaciones de derechos relacionados con el medio ambiente ${ }^{6}$.

El primer caso de temática ambiental ante el Sistema Interamericano de Derechos Humanos fue el caso Yanomami contra Brasil (Caso 7615, Resolución 12 de 1985) ${ }^{7}$, en el que la Comisión recibió una denuncia contra el Estado brasileño por la construcción de la "Rodovia Transamazónica" (actual BR 201, Perimetral Norte) en el interior de la Tierra Indígena Yanomami ${ }^{8}$. Este caso se presentó ante la Comisión el 15 de diciembre de 1980, siendo peticionarios Tim Coulter (director ejecutivo, Indian Law Resource Center),

\footnotetext{
${ }^{5}$ TEIXEIRA, G., O greening no sistema interamericano de direitos humanos, Curitiba, Juruá, 2011, p. 21.

${ }^{6}$ DESGAGNE, R., Integrating environmental values into the European Convention on Human Rights, American Journal of International Law, 1995, p. 280.

${ }^{7}$ El documento original íntegro puede encontrarse en el sitio web de la Corte Interamericana de Derechos Humanos (Corte IDH). Recuperado el 16 de diciembre de 2015, de

$<$ http://www.cidh.oas.org/Indigenas/JURISPRUDENCIA/CASOS\%20CIDH/4.CASO.7615.BRASIL.doc>.

${ }^{8}$ Comisión Interamericana de Derechos Humanos (CIDH). Caso Yanomami, Resolución núm. 12/85, caso $\mathrm{N}^{\mathrm{o}} 7615$ (Brasil), 5 de marzo de 1985. Recuperado el 16 de diciembre de 2015, de $<$ http://www.cidh.oas.org/annualrep/84.85sp/Brasil7615.htm>.
} 
Edward J. Lehman (director ejecutivo, American Anthropological Association), Barbara Bentley (directora, Survival International), Shelton H. Davis (director, Anthropology Resource Center) y George Krumbhaar (acting president, Survival International, EE. UU.), entre otros. La petición alegaba que se habían violado los derechos humanos del pueblo indígena yanomami, especialmente algunos de los derechos recogidos en la Declaración Americana de los Derechos y Deberes del Hombre de 1948, concretamente, en el artículo I (derecho a la vida, a la libertad, a la seguridad y a la integridad de la persona), el artículo II (derecho a la igualdad ante la ley), el artículo III (derecho a la libertad religiosa y de culto), el artículo XI (derecho a la preservación de la salud y al bienestar), el artículo XII (derecho a la educación), el artículo XVII (derecho al reconocimiento de la personalidad jurídica y de los derechos civiles) y el artículo XXIII (derecho a la propiedad).

El caso Yanomami es el resultado del plan de explotación y desarrollo de la región amazónica aprobado en 1960 y que en 1973 dio origen a la construcción de la Autovía Nacional BR 210. Durante las obras de la autovía transamazónica se hallaron múltiples minas y yacimientos de minerales en el interior de la Tierra Indígena Yanomami. Estos hallazgos atrajeron a la región numerosas compañías mineras y mineros independientes que iban en búsqueda de su tesoro, sin que existiera ningún control por parte del Gobierno, lo que provocó que miles de indígenas fueran asesinados o expulsados de sus casas y su territorio, cuya demarcación oficial solo se propuso en 1979 y en 1985, cuando la Comisión todavía no había concluido el análisis del caso. De modo que solo fue posible que este caso llegara ante la Corte Interamericana de Derechos Humanos porque Brasil reconoció la competencia de esta en una fecha tan tardía como 1992. Este caso ilustra muy bien la actuación de los Estados, que favorecen los intereses económicos y políticos de los grupos más poderosos en detrimento de los derechos y las garantías de comunidades enteras, especialmente las más vulnerables, con poco acceso a los medios para su defensa. Es importante subrayar que los peticionarios de este caso eran todos extranjeros e investigadores que conocían muy bien la realidad del pueblo indígena yanomami y que, por ello, también habían sido expulsados de la zona por las compañías mineras y los mineros autónomos.

Por desgracia, Brasil no es el único país acusado de violación de derechos de los pueblos 
indígenas por la construcción de grandes infraestructuras. Otros casos planteados ante la Comisión Interamericana de Derechos Humanos que cabe destacar son el caso Mayas de Toledo contra Belice, por una concesión de explotación de petróleo y madera en el interior de tierras indígenas (caso 12.053, de 12 de octubre de 2004 - Informe 40 de 2004) $)^{9}$; el caso Mateo Huanchor contra Perú, por haber autorizado a una compañía minera a que utilizara un territorio indígena como vertedero de residuos tóxicos (Petición 504 de 2003, Informe 69 de 2004) ${ }^{10}$; y el emblemático caso del Pueblo Inuit contra EE. UU. por la alegación de que el calentamiento global viola su calidad de vida y varios de sus derechos humanos (Petición 1413 de 2005) ${ }^{11}$. Estos casos, aunque no tengan relación directa con la construcción de grandes obras de infraestructura, demuestran que el Sistema Interamericano haz un esfuerzo para amparar la protección del medio ambiente, una vez que los impactos sobre la vida, salud, seguridad y derechos de las comunidades autóctonas no pueden ser desechados.

Así pues, el caso Belo Monte no es un caso aislado en el Sistema Interamericano de Derechos Humanos. Se trata de un caso más de violaciones sistemáticas de derechos humanos provocadas por los Estados en beneficio del "desarrollo económico" y del "progreso", estando habitualmente las comunidades indígenas más expuestas a violaciones sistemáticas de los derechos humanos, las cuales no terminan con el fin de las obras, sino que perduran en el tiempo y generan una serie de nuevas violaciones ${ }^{12}$.

El fallo de 28 de noviembre de 2007 emitido por la Corte Interamericana de Derechos Humanos en el caso Saramaka contra Surinam ilustra lo dicho anteriormente de manera

\footnotetext{
${ }^{9}$ CIDH. Informe núm. 40/04. Caso 12.053. Fondo. Comunidades indígenas mayas del distrito de Toledo. Belice. 12 de octubre de 2004. Recuperado el 16 de diciembre de 2015, de $<$ https://www.cidh.oas.org/annualrep/2004sp/Belize.12053.htm>.

${ }^{10}$ CIDH. Informe núm. 69/11. Petición 10.949. Admisibilidad. Magda Mateo Bruno. Perú. 31 de marzo de 2011. Recuperado el 16 de diciembre de 2015, de http://www.oas.org/es/cidh/decisiones/2011/PEAD10949ES.doc

${ }^{11}$ Petition to the Inter American Commission on Human Rights seeking relief from Violations resulting from Global Warming caused by Acts and Omissions of The United States. La Petición fue codificada con el núm. P-1413-05, 7 de diciembre de 2005. La petición fue rechazada por la CIDH por no aportar suficientes pruebas del daño ocasionado. Recuperado el 16 de diciembre de 2015, de $<$ http://graphics8.nytimes.com/packages/pdf/science/16commissionletter.pdf $>$.

${ }^{12}$ FLEURY, L. C. y ALMEIDA, J., “A construção da Usina Hidrelétrica de Belo Monte: conflito ambiental e o dilema do desenvolvimento", Ambient. Soc., diciembre de 2013, vol. 16, núm. 4, p. 9.
} 
muy clara y evidente. Se trata de una denuncia ante el Sistema Interamericano de violaciones de los derechos humanos de los miembros de la comunidad indígena saramaka por la construcción de una hidroeléctrica en el interior de sus tierras ancestrales en la década de 1960. Los efectos negativos de esta obra aún persisten entre los saramakas, puesto que no han podido recuperar del todo las tierras que les habían sido expropiadas durante la obra. Además, no han recibido ninguna indemnización por dicha expropiación, y Surinam no ha adoptado ninguna medida dirigida a minimizar los efectos de la construcción de la obra, una hidroeléctrica en pleno funcionamiento.

En efecto, el Sistema Interamericano viene fallando desde hace mucho sobre el tema tratado en este trabajo, por lo que dispone de jurisprudencia consolidada sobre el concepto de propiedad que los pueblos indígenas tienen sobre sus tierras. Este no se limita a la definición de propiedad privada, individual e indemnizable para el bien del interés público, sino que la tierra para las comunidades indígenas supone más que su mera posesión, pues la consideran un bien innegociable cuya explotación debe atender a los recursos naturales disponibles y no a los intereses económicos de los Estados.

Aun así, cabe señalar que los Estados desarrollados son los que más violan dichos derechos, con prácticas que son un ejemplo de impunidad y violencia para la comunidad internacional. En este sentido, cabe mencionar el caso 11.140, Mary y Carrie Dann contra EE. UU., publicado por el Informe de la Comisión Interamericana de Derechos Humanos, de 27 de septiembre de $1999^{13}$, y reiteradamente publicado en los informes siguientes, sobre la omisión de los EE. UU. a la hora de reconocer la demanda y cumplir la decisión de la Comisión. Se trata de un caso de expropiación de las tierras indígenas de la comunidad Western por el Gobierno de los EE. UU. en la década de 1990 y su concesión a compañías mineras de exploración de oro y empresas de exploración de energía geotérmica, petróleo y gas. Asimismo, se realizaron pruebas militares y se expropió el uso y goce de los recursos hídricos del interior de la tierra de los Western Shoshone. Todo ello sin que tuviera lugar el debido proceso legal ni se concedieran las indemnizaciones

\footnotetext{
${ }^{13}$ CIDH. Informe núm. 99/99. Caso 11.140. Mary y Carrie Dann. Estados Unidos. 27 de septiembre de 1999. Recuperado el 16 de diciembre de 2015, de $<$ http://www.cidh.oas.org/Indigenas/JURISPRUDENCIA/CASOS CIDH/17.CASO.11140.EEUU.ADM.doc $>$.
} 
oportunas.

La Comisión Interamericana, por su carácter único, es el organismo más sensibilizado en materia de violación de los derechos de los pueblos indígenas. Uno de sus departamentos, la Relatoría Especial para la Defensa de los Derechos de los Pueblos Indígenas, tiene registradas denuncias por grandes obras en tierras indígenas desde hace muchos años, en especial a partir de la década de 1990. El caso del Parque Natural Metropolitano, en Panamá $^{14}$, es otro buen ejemplo de una concesión otorgada por el Estado para la construcción de una infraestructura - una autovía - que pone en peligro un espacio natural - en este caso, una reserva ecológica, científica y cultural reconocida por la Ley núm. 8 de 1985 del Estado de Panamá-. La denuncia fue recibida por la Comisión en 1995, si bien el caso fue declarado inadmisible por cuestiones de forma (representación in abstracto).

Efectivamente, en los últimos años se ha avanzado mucho en relación con el reconocimiento por parte de la Corte Interamericana de Derechos Humanos del derecho a un medio ambiente sano como derecho humano. Los casos de graves violaciones de los derechos humanos por la construcción de grandes infraestructuras durante la década de 1990 están llegando actualmente a la Corte, que en los últimos años ha emitido sobre este tema cuatro sentencias y una medida cautelar, dos de ellas en el 2014. El primer caso de temática ambiental resuelto por la Corte Interamericana de Derechos Humanos fue el caso Mayagna (Sumo) Awas Tingni contra Nicaragua, planteado ante la Corte a finales de la década de 1990 y que se concluyó con una sentencia condenatoria emitida el 1 de febrero de 2000. Este caso giraba en torno a la concesión que el Estado nicaragüense había otorgado a la empresa Sol de Caribe, S. A., para explotar madera en el interior de tierras indígenas, sin consultar previamente a los miembros de la comunidad indígena (29 Corte IDH. Caso de la comunidad Mayagna (Sumo) Awas Tingni contra Nicaragua) ${ }^{15}$.

Por su parte, la primera medida cautelar dictada por la Corte en materia ambiental se

\footnotetext{
${ }^{14}$ CIDH. Informe núm. 88/03. Petición 11.533. Inadmisibilidad. Parque Natural Metropolitano. Panamá. 22 de octubre de 2003. Recuperado el 16 de diciembre de 2015, de

$<$ http://www.cidh.oas.org/annualrep/2003eng/Panama.11533.htm>.

${ }^{15}$ Corte IDH. 29 IACHR. Caso de la comunidad Mayagna (Sumo) Awas Tingni contra Nicaragua. Sentencia de 1 de febrero de 2000 (Excepciones Preliminares). Serie C núm. 66. Recuperado el 16 de diciembre de 2015, de <http://www.corteidh.or.cr/docs/casos/articulos/Seriec_66_esp.pdf $>$.
} 
produjo a raíz de la petición de la Comisión y de nuevo está relacionada con la construcción de grandes infraestructuras. Esta medida se adoptó en el caso Cuatro Comunidades Indígenas Ngöbe y sus miembros (MC de 28 de mayo de 2010). En 2008, la Comisión recibió la denuncia de que los pueblos indígenas del valle del río Changuinola se veían perjudicados por la construcción de una planta hidroeléctrica en el interior del territorio indígena ngöbe.

El Gobierno de Panamá otorgó a la empresa AES-Changuinola una concesión por un período de 20 años para la construcción de varias presas a lo largo de la curva del río Teribe-Changuinola, en el interior de la tierra indígena de los pueblos ngöbe. La Comisión Interamericana declaró la admisibilidad de la denuncia y publicó su decisión en su Informe 75 de 2009. Sin embargo, al no adoptar Panamá las medidas necesarias para que cesaran las violaciones de los derechos de los pueblos ngöbe, la Comisión solicitó a la Corte que dictara una medida cautelar. El caso aún está siendo monitorizado por el Sistema Interamericano de Derechos Humanos.

La segunda sentencia emitida por la Corte en materia ambiental también está relacionada con grandes infraestructuras y resuelve el caso del Pueblo Indígena Kichwa de Sarayaku y sus miembros contra Ecuador. En este caso se trata de la concesión a compañías mineras y empresas petroleras para explotar el interior de tierras indígenas sin consulta previa a sus habitantes, con el agravante de que se vierten residuos tóxicos en el suelo y en el agua (Petición 503 de 2003 e Informe 69 de 2004). El fallo de la Corte se emitió el 27 de junio de 2012 y supuso la condena de Ecuador por dichas violaciones ${ }^{16}$.

El tercer caso se refiere a la Sentencia de 29 de mayo de 2014, sobre el caso Caso Norín Catrimán y otros (dirigentes, miembros y activistas del pueblo indígena mapuche) contra Chile, que trata de la construcción de una central hidroeléctrica en la provincia de BíoBío ${ }^{17}$, VIII Región de Chile. En Bío-Bío, las comunidades ribereñas y los pueblos

\footnotetext{
${ }^{16}$ Corte IDH. Pueblo indígena Kichwa de Sarayaku contra Ecuador. Sentencia de 27 de junio de 2012. Fondo y reparaciones. Serie C núm. 245. Recuperado el 16 de diciembre de 2015, de $<$ http://corteidh.or.cr/docs/casos/articulos/seriec_245_esp.pdf>.

${ }^{17}$ Corte IDH. Caso Norín Catrimán y otros (dirigentes, miembros y activistas del pueblo indígena mapuche) contra Chile. Sentencia de 29 de mayo de 2014. Fondo, reparaciones y costas. Serie C núm. 279. Recuperado el 16 de diciembre de 2015, de $<\mathrm{http}: / /$ www.corteidh.or.cr/docs/casos/articulos/seriec_279_esp.pdf $>$.
} 
indígenas perjudicados por la construcción de la planta hidroeléctrica se organizaron en una fuerte y presente oposición al Gobierno y las constructoras concesionarias. Para reprimir este movimiento, el Estado chileno recurrió a la Ley Antiterrorista, lo que dio lugar a numerosas detenciones arbitrarias. La Sentencia de la Corte Interamericana está basada en la violación de los derechos a la libertad de expresión y asociación y reunión, e identifica los recursos ilegales utilizados por los Estados en la defensa de sus intereses.

La última sentencia de la Corte Interamericana de Derechos Humanos en materia ambiental relacionada con grandes obras trata del caso de los Pueblos Indígenas Kuna de Madungandí y Emberá de Bayano y sus miembros, conocido como el caso Kuna contra Panamá. La Sentencia se publicó el 14 de octubre de 2014 y constituye un resumen muy claro de lo que el Sistema Interamericano entiende por violaciones de derechos humanos cuando la construcción de grandes obras amenaza la vida, la integridad, la familia, la salud y la propiedad de grupos vulnerables. Este caso se refiere a la construcción de la presa hidroeléctrica Bayano en el interior de tierras indígenas demarcadas y a la total falta de respeto del Estado de Panamá por los habitantes de este territorio.

\section{LA IMPORTANCIA PARA BRASIL Y EL MUNDO DE LA LUCHA POR EL RÍO XINGÚ: EL SOCIOAMBIENTALISMO}

Socioambientalismo es un término controvertido que viene suscitando algunas discusiones en el mundo académico ${ }^{18}$. Dicho término surge en Brasil a finales de la década de 1980 como resultado de la articulación entre los movimientos sociales y los ambientales ${ }^{19}$. La génesis del movimiento socioambiental se halla en el reconocimiento de la importancia que reviste la adopción de medidas protectoras del medio ambiente. Este movimiento se inició en la década de 1960 cuando, después de la Segunda Guerra Mundial, las relaciones entre medio ambiente y desarrollo comenzaron a estudiarse ${ }^{20}$. En

\footnotetext{
${ }^{18}$ CASTRO, F. y FUTEMMA, C. (org.), Governança Ambiental no Brasil - entre o socioambientalismo e a economia verde, Editorial Paco, São Paulo, 2015, p. 23.

${ }^{19}$ MARÉS, C.F., "Introdução ao Direito Socioambiental", Lima, André, O Direito para o Brasil Socioambiental, Editora SafE, 2002, p. 4.

${ }^{20}$ La preocupación ambiental en Brasil es bastante anterior a la época del surgimiento del socioambientalismo, dado que desde finales del siglo XVIII hasta finales del siglo XIX ya existía una
} 
1972, la Declaración de Estocolmo utilizó por primera vez la palabra ecodesarrollo con el sentido de desarrollo ecológicamente orientado ${ }^{21}$. Este término ha sido utilizado para orientar los trabajos del Programa de las Naciones Unidas para el Medio Ambiente (PNUMA). El término ecodesarrollo ha sido sustituido por la expresión desarrollo sostenible, utilizada por primera vez en 1987 en el Informe Brundtland. Este último término se define como el "crecimiento que satisface las necesidades de las generaciones presentes sin comprometer la capacidad de las generaciones futuras de satisfacer sus propias necesidades" 22 .

Sin embargo, el término no está exento de críticas. Hay diversas variables a considerar cuando se busca medir el grado de desarrollo de un país. ¿Se trata de una sostenibilidad que busca proporcionar unas condiciones satisfactorias a la existencia, a las diferentes culturas, a los ecosistemas, a la biodiversidad...? ¿Se trata del desarrollo de las personas en ámbitos como la esperanza de vida, el nivel de educación, la igualdad material o el económico? Estos planteamientos generan reflexiones sobre lo que debe ser desarrollado y lo que debe ser sustentado, y sobre cómo relacionar lo que se desea sostener con lo que se desea desarrollar. Para ilustrar la cuestión, podemos utilizar un ejemplo de las relaciones entre economía y medio ambiente: ¿cuál es el límite de extracción de bienes comunes y no renovables en beneficio del crecimiento económico? Estas son cuestiones y planteamientos de difícil solución pacífica ${ }^{23}$.

La Constitución brasileña de 1988, mediante la cual se reinstaura la democracia en el país, permitió que nuevos actores, entre ellos, los pueblos indígenas, las comunidades ribereñas y los cimarrones (quilombolas), pudieran dialogar entre sí y reivindicar los derechos olvidados en los años de la dictadura. En este contexto nace el movimiento de lucha por el río Xingú (“a luta pelo Rio Xingú”) como un intento para impedir el

\footnotetext{
“manifestación de crítica al modelo de explotación colonial amparada en el latifundio, la esclavitud, las plantaciones intensivas y los maltratos a la tierra y a la consecuente devastación ambiental provocada por este modelo". MARÉS, C.F., A função social da terra, Sergio Antonio Fabris Editor, Porto Alegre, 2003, p. 12.

${ }^{21}$ BRYANT, R. y BAILEY, S., Third World Political Ecology, Routledge, 1997, p. 45.

${ }^{22}$ SANTILLI, J., Socioambientalismo e novos direitos: proteção jurídica à diversidade biológica e cultural, Ed. Peirópolis, 2005, p. 89.

${ }^{23}$ DOBSON, A., Justice and the environment - conceptions of environmental sustainability and dimensions of social justice, Oxford University Press, 1998, p. 79.
} 
desarrollo y la construcción de grandes proyectos en la región amazónica ${ }^{24}$ que pudieran desplazar comunidades enteras y provocar aún más daños a la población amazónica, especialmente a las comunidades indígenas ${ }^{25}$. El primer acto de este movimiento tuvo lugar en 1989 con la Primera Reunión de los Pueblos Indígenas de Xingú. El movimiento reunió a más de tres mil personas, seiscientas cincuenta de las cuales eran indígenas, habitantes ribereños, cimarrones, activistas ambientales, defensores de derechos humanos, mujeres y niños. Fue considerado un hito en lo que respecta al movimiento socioambiental en Brasil por reunir a diversos grupos con un objetivo en común ${ }^{26}$.

El socioambientalismo fue construido a partir de la idea de que las políticas públicas ambientales deben incluir e involucrar a las comunidades locales, poseedoras de conocimientos y prácticas de gestión ambiental. Más allá, se desarrolló basado en el concepto de que en un país pobre, con muchas desigualdades sociales, [...] se debe promover la sostenibilidad no solo desde una perspectiva estrictamente ambiental, esto es, que la sostenibilidad social debe también contribuir a la reducción de la pobreza y de las desigualdades sociales y a la promoción de valores como la justicia social y la equidad. Además, el nuevo paradigma de desarrollo propugnado por el socioambientalismo debe promover y valorar la diversidad cultural para consolidar el proceso democrático en el país, con una amplia participación social en la gestión ambiental ${ }^{27}$.

Como movimiento, el socioambientalismo fomenta la adopción de nuevos derechos, los derechos socioambientales, que rompen con los paradigmas de la doctrina jurídica tradicional, formalista, supuestamente neutral, de contenido patrimonial y contractualista.

\footnotetext{
${ }^{24}$ Durante los casi 30 años de dictadura brasileña el Gobierno militar promovió obras faraónicas en todo el territorio nacional, entre las cuales se encuentran la presa de Itaipú y el puente del río Niterói, infraestructuras que siempre se citan como ejemplos de "éxito" económico para encubrir los fracasos de muchos otros proyectos llevados a cabo en el país, especialmente en la región amazónica, como, por ejemplo, la carretera transamazónica, el proyecto Randam Brasil o el proyecto de construcción de varias centrales hidroeléctricas en la cuenca del río Xingú. FURTADO, C., $O$ mito do desenvolvimento econômico, Paz e Terra, Río de Janeiro, 1974, p. 94.

${ }^{25}$ COLCHESTER, M., Dams, Indigenous People and vulnerable ethnic minorities, Forest Peoples Programme, Sudáfrica, 2000, p. 143.

${ }^{26}$ SANTOS, L. A. O. y ANDRADE, L. M. M. de, As hidrelétricas do Xingú e os povos indígenas, Comissão Pro-Índio de São Paulo, São Paulo, 1988, p. 28.

${ }^{27}$ GUIMARÃES, R. P., "A ética da sustentabilidade e a formulação de políticas de desenvolvimento", Diniz et ál. (orgs.), O desafio da sustentabilidade: um debate socioambiental no Brasil, Editora Fundação Perseu Abramo, São Paulo, 2001, p. 35.
} 
Los nuevos derechos tienen una naturaleza emancipadora, pluralista, colectiva e indivisible, e imponen nuevos desafíos a la ciencia jurídica ${ }^{28}$.

En este contexto, la reanudación de la explotación en la región amazónica, especialmente en la cuenca del río Xingú, ha hecho aflorar traumas y cicatrices no curados en Brasil ${ }^{29}$. El caso Belo Monte se ha convertido en un ejemplo representativo de situación contra la que el movimiento socioambientalista venía luchando desde hacía décadas, mientras que el río Xingú vuelve a ser el nexo de unión entre líderes locales, regionales, nacionales e internacionales a favor de las comunidades afectadas ${ }^{30}$.

La repercusión del caso Belo Monte, sobre todo gracias a la presa internacional —la prensa nacional sofoca cualquier intento de visibilidad social del problema-, ha contribuido a la coordinación entre los grupos sociales y ambientales, que han adquirido una mayor importancia y han buscado instrumentos de tutela jurídica y apoyo en organizaciones nacionales e internacionales de derechos humanos. Así, diversas ONG y asociaciones civiles han presentado acciones judiciales ante el poder judicial brasileño, lo que ha fortalecido la unidad de los movimientos que reivindican, sobre todo, la supervivencia del río Xingú y de las comunidades que allí viven y el respeto a los trabajadores y las tradiciones locales. Se trata de una lucha difícil que hasta el momento ha obtenido como resultado la unificación en una sola voz de todos los defensores de los derechos humanos, de las minorías y de los activistas ambientales contra la barbarie y el genocidio allí practicados. Belo Monte representa en sí un delito contra la naturaleza de proporciones incalculables ${ }^{31}$.

El impacto de Belo Monte en Brasil aún no se puede medir. El caso ha sido llevado al Sistema Interamericano de Derechos Humanos por su impacto, que afecta también a otros

\footnotetext{
${ }^{28}$ MARÉS, C.F., "Introdução ao Direito Socioambiental", Lima, A., O Direito para o Brasil Socioambiental, Editora SafE, 2002, p. 32.

${ }^{29}$ SILVA, E., "Transformações sócio-ambientais e a problemática ambiental no Brasil: o caso das hidrelétricas", Caminhos da Geografia (UFU. Online), 2007, v. 8, núm. 23, p. 38.

${ }^{30} \mathrm{MC}$ CULLY, P., Silenced rivers: the ecology and politics of large dams, Zed Books, Londres, Reino Unido, 2001, p. 67.

${ }^{31}$ FAINGUELERNT, M., "Belo Monte. Reflexiones críticas sobre la trayectoria histórica del proyecto de la hidroeléctrica y los escollos de las licencias ambientales en el Brasil", Revista Contrapunto. Bienes comunes. Saqueo y resistencias, Universidad de la República, Montevideo, junio de 2013, p. 133.
} 
países de América del Sur ${ }^{32}$, en la región amazónica. También se ha convertido a nivel internacional, entre otros conflictos por causas ambientales, en un caso emblemático de degradación y muerte. La violencia contra la naturaleza es una forma de violencia contra el ser humano y es mediante esta concepción que la Corte Interamericana de Derechos Humanos, cuya competencia se restringe a la aplicación de los tratados de derechos humanos ratificados por los Estados parte, puede, como ya lo ha hecho en ocasiones anteriores, admitir y resolver este caso $^{33}$.

De hecho, el greening o ambientalización del derecho internacional refleja las aspiraciones del movimiento socioambiental, integrando sociedad y naturaleza, seres humanos y medio ambiente, en una lucha común por la supervivencia cuya consecuencia inmediata es admitir que las cortes y los tribunales internacionales tienen competencia para recibir, analizar y juzgar casos de violación y degradación ambiental porque los Estados han ratificado tratados que contemplan tal posibilidad ${ }^{34}$.

Comprender el caso Belo Monte resulta, por lo tanto, imprescindible en la medida en que refuerza la comprensión del Sistema Interamericano al reconocerse la existencia de una conexión indisoluble entre el medio ambiente y los seres humanos, lo que permite a los nuevos actores contar con un nuevo canal de acceso a la justicia.

\section{PARA COMPRENDER EL CASO BELO MONTE: DESDE BRASIL HACIA EL SISTEMA INTERAMERICANO}

Belo Monte es el nombre dado a una presa en construcción en el estado de Pará, en el norte de Brasil. Es un viejo tema constante en la lista de obras que nos sitúan en un nivel superior en la escala de desarrollo de los países. Desde la década de 1970 el Gobierno

\footnotetext{
${ }^{32}$ DOUROJEANNI, M. J., "Human Impact on Protected Areas of the Peruvian Amazon", Wuerthner, G., Crist, E. y Butler, T. (eds.), Protecting the Wild: Parks and Wilderness, the Foundation for Conservation, Island Press-Center for Resource Economics, Washington D.C., Estados Unidos de América, 2015, pp. 217.

${ }^{33}$ SALLES CAVEDON-CAPDEVILLE, F. d., "L'écologisation du Système Interaméricain des Droits de l'Homme (SIDH): commentaire de la jurisprudence récente (2010-2013)", Revue juridique de l'environnement, vol. 39, núm. 3, 2014, p. 489-511.

${ }^{34}$ GARCÍA RAMÍREZ, S. y CASTAÑEDA HERNÁNDEZ, M. (coord.), Recepción nacional del derecho internacional de los derechos humanos y admisión de la competencia contenciosa de la Corte Interamericana, Universidad Nacional Autónoma de México, México, 2009.
} 
militar estaba estudiando la posibilidad de crear varios proyectos para la generación de energía a lo largo del río Xingú ${ }^{35}$.

Se debe tener en cuenta que más del 70\% del suministro de energía en Brasil proviene de la energía hidroeléctrica, llegando al 75\% en 2010. La dependencia de Brasil de este tipo de energía tiene explicaciones históricas derivadas de la rica oferta de ríos apropiados para la producción de electricidad. Con el tiempo, los políticos se dieron cuenta de que la cuestión energética era de importancia entre los votantes. Por lo tanto, el problema siempre ha estado presente entre los planes de desarrollo. En el Plan de Aceleración del Crecimiento 1 (PAC1) se planificaron veinte centrales hidroeléctricas, mientras que en el Plan de Aceleración del Crecimiento 2 (PAC2), otras veinte. Aunque la construcción de la central hidroeléctrica de Belo Monte se planteó por primera vez en la década de 1970, la obra dejó el papel en la década de $2000^{36}$.

Belo Monte se está construyendo a orillas del Xingú, un río de la vertiente derecha del Amazonas, la más adecuada para este tipo de infraestructuras. Se trata de una región del país con baja densidad de población que es el hogar de algunas tribus y de poblaciones cuyo origen se remonta a la época en que la economía giraba en torno a la goma de caucho. Con el declive de esta industria, una serie de antiguos trabajadores de la industria del caucho se asentó en esta región. Hay por lo menos tres municipios afectados por las obras, a saber, Vitória do Xingú, Altamira y Brasil Novo, y posiblemente otros dos, Senador José Porfirio y Anapu ${ }^{37}$.

La polémica por la construcción de la presa se debe a que es necesario hacer un depósito de agua, por lo que el río es represado. Ello supone la inundación una gran área. Por otro lado, en el caso de Belo Monte, el curso del río está siendo desviado y una alzada de aproximadamente cien kilómetros dejará de existir. Hay dos grupos perjudicados, las personas afectadas por la inundación antes de la presa y las que lo han sido por la sequía

\footnotetext{
${ }^{35}$ FLEURY y ALMEIDA, “A construção...” cit., p.149.

${ }^{36}$ PINHEIRO, M. F. B., Problemas sociais e institucionais na implantação de hidrelétricas: seleção de casos recentes no Brasil e casos relevantes em outros países, Campinas, SP: [s.n.], 2007 [Dissertacao de Mestrado. Programa de Pós-Graduaçao em Engenharia Mecanica. UNICAMP. Brasil].

${ }^{37}$ CUNHA DE ANDRADE, D. y FERREIRA VALLE, L., "Impacts of the Belo Monte hydroelectric dam construction on pioneer vegetation formations along the Xingú River, Pará State, Brazil", Braz. J. Bot., 2012, vol. 35, núm. 2, p. 19.
} 
río abajo de la presa. Desde el punto de vista ambiental, los principales impactos son las inundaciones y las sequías, que provocan cambios drásticos en la flora y la fauna, lo que hace la vida insoportable para muchas especies y a menudo para las personas ${ }^{38}$.

Se han llevado a cabo varias consultas y audiencias públicas por parte del Instituto Brasileño de Medio Ambiente y Recursos Naturales Renovables (IBAMA), además de reuniones con el órgano Fundación Nacional del Indio (FUNAI), las familias y los pueblos indígenas de las tierras afectadas, las instituciones gubernamentales y varias entidades de protección ambiental.

Se espera que la infraestructura genere hasta $11.000 \mathrm{MW}$, si bien con un promedio de 4.500 MW, lo que significa que, a pesar de que su capacidad es similar a la de Itaipú —la segunda mayor hidroeléctrica del mundo, con 14.000 MW—, la generación de energía real estará muy por debajo de la de Itaipú. Además, otro detalle que hace que la construcción de esta hidroeléctrica sea tan importante es que a esta primera presa se le añadirán otras, es decir, si se permite su construcción, se abrirá la puerta a otras nuevas puesto que, para ser plenamente eficaz, Belo Monte requerirá otros embalses ${ }^{39}$.

Para realizar la obra, se perjudicará a miles de indígenas y comunidades ribereñas, además de a numerosas especies de animales y plantas. Los desplazamientos provocados puede que no conlleven la extinción de las poblaciones, pero sí al menos de sus culturas. Respecto a las poblaciones afectadas, uno de los temas más preocupantes es la imposibilidad de acceder al conocimiento tradicional acumulado oralmente desde hace generaciones ${ }^{40}$.

En Brasil, en la actualidad hay más de quince demandas judiciales en trámite en los tribunales brasileños en relación con la construcción de Belo Monte. En general, las demandas alegan el incumplimiento de la legislación y los procedimientos legales para autorizar una gran obra como la de Belo Monte. Un ejemplo es el análisis del impacto ambiental o del impacto en las personas que viven en la región. La última demanda sobre

\footnotetext{
${ }^{38}$ FRANCO, F.C.O. y FEITOSA, M. L. A., "Desenvolvimento e direitos humanos: marcas de inconstitucionalidade no processo Belo Monte", Rev. direito GV, junio de 2013, vol. 9, núm. 1, p. 98.

${ }^{39}$ CARVALHO et al., "Levels..." cit., p. 1158.

${ }^{40}$ SANTOS y ANDRADE, As hidrelétricas ..., cit., p. 34.
} 
la construcción se resolvió en 2006. El argumento principal era que la comunidad indígena no había sido debidamente escuchada y que sus quejas no habían sido consideradas conforme a lo que determina la ley brasileña. A pesar de que el fallo dio la razón a la comunidad indígena, el Poder Judicial no dictaminó la interrupción de las obras porque estas ya se hallaban muy avanzadas y su suspensión hubiera causado un daño aún más grande ${ }^{41}$.

El caso llegó el Sistema Interamericano de Derechos Humanos mediante la Medida Cautelar 382, de 2010, y fue denominado por la Comisión Interamericana de Derechos Humanos así: "Comunidades indígenas de la cuenca del río Xingú, entre las cuales se incluyen: Arara da Volta Grande do Xingú; Juruna de Paquiçamba; Juruna del Kilómetro 17; Xikrin de Trincheira Bacajá; Asurini de Koatinemo; Kararaô y Kayapó de la tierra indígena Kararaô; Parakaã de Apyterewa; Araweté del Igarapé Ipixuna; Arara de la tierra indígena Arara; Arara de Cachoeira Seca; y las comunidades indígenas en aislamiento voluntario de la cuenca del Xingú". La petición solicitó medidas cautelares alegando que la vida y la integridad de las comunidades indígenas y ribereñas estaban en riesgo por el impacto de la construcción de la central hidroeléctrica de Belo Monte ${ }^{42}$.

La Comisión Interamericana de Derechos Humanos pidió a Brasil, el 1 de abril de 2011, la suspensión inmediata del proceso de autorización de la central hidroeléctrica de Belo Monte con el fin de impedir la ejecución de cualquier obra material hasta que se cumplieran las siguientes condiciones mínimas:

(1) realizar procesos de consulta, en cumplimiento de las obligaciones internacionales de Brasil, en el sentido de que la consulta sea previa, libre, informada, de buena fe, culturalmente adecuada, y con el objetivo de llegar a un acuerdo, en relación con cada una de las comunidades indígenas afectadas, beneficiarias de las presentes medidas cautelares;

\footnotetext{
${ }^{41}$ FRANCO y FEITOSA, "Desenvolvimento...” cit., p. 8.

${ }^{42}$ VENTURA, D. y CETRA ORTIZ, R., "O Brasil e o sistema interamericano de direitos humanos: de Maria da Penha a Belo Monte", Silva Filho, J.C. y Torelly, M. (orgs.), Justiça de Transição nas Américas: olhares interdisciplinares, fundamentos e padrões de efetivação, Forum, Belo Horizonte, 2013, p. 3. Documento de difusión gratuita. Recuperado el 16 de diciembre de 2015, de $<$ http://www.conectas.org/arquivossite/Ventura\%20Cetra\%20O\%20Brasil\%20e\%20o\%20SIDH\%202012\%20(2)(1).pdf>.
} 
(2) garantizar que, en forma previa a la realización de dichos procesos de consulta, para asegurar que la consulta sea informada, las comunidades indígenas beneficiarias tengan acceso a un Estudio de Impacto Social y Ambiental del proyecto, en un formato accesible, incluyendo la traducción a los idiomas indígenas respectivos;

(3) adoptar medidas para proteger la vida e integridad personal de los miembros de los pueblos indígenas en aislamiento voluntario de la cuenca del Xingú, y para prevenir la diseminación de enfermedades y epidemias entre las comunidades indígenas beneficiarias de las medidas cautelares como consecuencia de la construcción de la hidroeléctrica Belo Monte, tanto de aquellas enfermedades derivadas del influjo poblacional masivo a la zona, como de la exacerbación de los vectores de transmisión acuática de enfermedades como la malaria ${ }^{43}$.

Brasil ha considerado las medidas apresuradas e injustificables por parte de la Comisión y ha solicitado tiempo para contestarlas. Sin embargo, al hacerlo, ha adoptado una posición defensiva de los intereses nacionales y ha afirmado solamente que haría todo lo posible para cumplir las recomendaciones de la Comisión. La posición de Brasil, hasta entonces siempre favorable al diálogo con el Sistema Interamericano, ha cambiado. En este sentido, el Gobierno brasileño ha pasado a adoptar una postura arrogante y desafiante frente al Sistema, sin interrumpir las obras ni proponer una negociación sobre el caso a nivel internacional.

La Comisión Interamericana ha intentado el diálogo. El 29 de julio de 2011, durante el 142. ${ }^{\circ}$ período de sesiones, la Comisión examinó el MC 382-10 y modificó la petición de medidas cautelares, eliminando el requisito de la interrupción de las obras y pidiendo al Gobierno brasileño que únicamente cumpliera lo siguiente:

1) Adopte medidas para proteger la vida, salud e integridad personal de los miembros de las comunidades indígenas en situación de aislamiento voluntario de la cuenca del Xingú, y de la integridad cultural de dichas comunidades, que incluyan acciones efectivas de implementación y ejecución de las medidas jurídico-formales ya existentes, así como el diseño e implementación de medidas de mitigación específicas para los efectos que tendrá la construcción de la represa Belo Monte

\footnotetext{
${ }^{43} \mathrm{CIDH}$. Medidas cautelares outorgadas pela CIDH no ano 2011. (Ordem cronológica, começando pela última medida adotada). MC 382/10 - Comunidades Indígenas de la Cuenca del Río Xingú, Pará, Brasil. Recuperado el 16 de diciembre de 2015, de <http://www.cidh.oas.org/medidas/2011.port.htm>.
} 
sobre el territorio y la vida de estas comunidades en aislamiento;

2) Adopte medidas para proteger la salud de los miembros de las comunidades indígenas de la cuenca del Xingú afectadas por el proyecto Belo Monte, que incluyan

(a) la finalización e implementación aceleradas del Programa Integrado de Salud Indígena para la región de la UHE Belo Monte, y

(b) el diseño e implementación efectivos de los planes y programas específicamente requeridos por la FUNAI en el Parecer Técnico 21/09, recién enunciados; y

3) Garantice la pronta finalización de los procesos de regularización de las tierras ancestrales de pueblos indígenas en la cuenca del Xingú que están pendientes, y adopte medidas efectivas para la protección de dichos territorios ancestrales ante la intrusión y ocupación por no indígenas, y frente a la explotación o deterioro de sus recursos naturales ${ }^{44}$.

Sin embargo, la Comisión constató que el choque entre los peticionarios y el Estado brasileño con respecto a la consulta previa de las personas afectadas y el consentimiento informado del proyecto de Belo Monte se había convertido en una discusión mucho más amplia que iba más allá del alcance del procedimiento de medidas cautelares.

El caso sigue en la Comisión Interamericana de Derechos Humanos. Si hubiera querido, la Comisión podría haber solicitado medidas cautelares ante la Corte Interamericana de Derechos Humanos. El caso deberá ser completado dentro de la Comisión con una decisión análoga a la del caso Yanomami, es decir, la admisibilidad de la queja y la publicación de informes del Gobierno brasileño. Se cree que la Comisión debe llevar el caso a la Corte Interamericana de Derechos Humanos, cuya sentencia no es diferente de la sentencia dictada en el caso Kuna contra Panamá, recientemente publicada en 2014. De hecho, la triste conclusión de todo esto es que ni siquiera el propio Sistema Interamericano tiene el poder para luchar contra la connivencia entre Estados y grandes corporaciones y que las violaciones de los derechos causadas por la construcción de grandes obras quedan impunes, lo que sería una muestra del efecto perverso del

\footnotetext{
${ }^{44} \mathrm{CIDH}$. Medidas cautelares outorgadas pela CIDH no ano 2011. (Ordem cronológica, começando pela última medida adotada). MC 382/10 - Comunidades Indígenas de la Cuenca del Río Xingú, Pará, Brasil. Recuperado el 16 de diciembre de 2015, de http://www.cidh.oas.org/medidas/2011.port.htm
} 
capitalismo contemporáneo: la obtención de beneficios en detrimento de la vida, la libertad, los derechos humanos y el futuro de la humanidad.

\section{CONCLUSIONES}

La construcción de grandes infraestructuras supone, evidentemente, un inmenso impacto en la vida de toda una sociedad. El argumento de que estas obras son necesarias debe ponerse en duda, y también cabe destacar que sus beneficiarios a menudo no son conscientes de las violaciones de los derechos de sus vecinos, compatriotas y compatriotas. De hecho, los grupos más vulnerables, como los afrodescendientes, los pueblos indígenas, las comunidades ribereñas o los pobres en general, son los más afectados por el desplazamiento forzado y la violencia de la pérdida no solo de su tierra, sino también de su legado, historia, tradiciones y sentido de pertenencia a una comunidad y un territorio.

La construcción de grandes proyectos en las Américas también se puede analizar desde el punto de vista del desarrollo de la tecnología y los recursos para llevarlos a cabo. De hecho, la construcción de grandes obras no es un fenómeno reciente y se considera uno de los logros más importantes de la humanidad. Las pirámides de Egipto, los castillos europeos, el canal de Panamá..., son solo algunos ejemplos de cómo la humanidad celebra más sus trofeos que a las personas ${ }^{45}$.

Al examinar diferentes casos en materia ambiental relacionados con grandes proyectos de construcción, se ha podido constatar la existencia de numerosos "Belo Monte": expropiaciones arbitrarias, desplazamientos forzados y numerosas violaciones de derechos humanos a causa de las obras de la Copa Mundial de Fútbol y los Juegos Olímpicos de Río de Janeiro; prácticas que ya habían sido denunciadas con motivo de la organización de la Copa Mundial de Fútbol en Sudáfrica. En Brasil, para supervisar dichas violaciones y ayudar a las víctimas se constituyó la Coordinación Nacional de los Comités Populares de la Copa del Mundo y los Juegos Olímpicos. La divulgación de las violaciones también llegó a las Naciones Unidas a través del Grupo de Trabajo sobre

\footnotetext{
${ }^{45}$ PINHEIRO, Problemas..., cit.
} 
Empresas y Derechos Humanos ${ }^{46}$.

Recientemente, el 17 de marzo de 2015, el CEJIL, junto con otras diez organizaciones, presentó una denuncia ante el Sistema Interamericano de Derechos Humanos en relación con violaciones de derechos humanos generalizadas como consecuencia del proyecto de construcción de un canal transoceánico en Nicaragua: un nuevo canal de Panamá. Las organizaciones expresaron su preocupación porque el Estado de Nicaragua no hubiera consultado previamente a los pueblos indígenas y afrodescendientes que viven en la zona de las obras. Se estima que alrededor de 120.000 personas se han visto desplazadas en la primera fase del proyecto ${ }^{47}$.

La construcción del acueducto Independencia en México también fue llevada a la justicia nacional por la desviación de más de 50 millones de metros cúbicos de agua del río Yaqui, en las tierras de la comunidad indígena yaqui. El desvío de agua pone en peligro la vida de esta comunidad indígena. El proyecto fue aprobado en 2011 y sigue su curso. En 2012 la comunidad indígena obtuvo un fallo favorable de la justicia regional y se espera la confirmación de la Corte Suprema de Justicia. La decisión, sin embargo, no contempla detener los trabajos.

Estos son solo algunos ejemplos de grandes obras que afectan a la vida de miles de personas, si bien sus resultados se defienden y han sido celebrados por ciertos grupos como grandes hazañas de la ingeniería, la gestión y la visión económica. El medio ambiente es el elemento desechable en la ecuación. Por consiguiente, el desarrollo sostenible es el gran desafío de este nuevo siglo y, por lo tanto, el gran proyecto que la humanidad debe emprender.

\footnotetext{
${ }^{46}$ BUSINESS AND HUMAN RIGHTS RESOURCE CENTRE. Abusos de derechos humanos relacionados con el Mundial de la FIFA del 2014 y los Juegos Olímpicos del 2016 en Brasil. 2014. Recuperado el 16 de diciembre de 2015, de <http://business-humanrights.org/es/abusos-de-derechoshumanos-relacionados-al-mundial-de-la-fifa-del-2014-y-los-juegos-ol\%C3\%ADmpicos-del-2016-enbrasil>.

${ }^{47}$ CENTRO POR LA JUSTICIA Y EL DERECHO INTERNACIONAL (CEJIL). Organizaciones denunciaron ante CIDH violación de derechos humanos por la construcción del canal en Nicaragua. Washington, D.C., 17 de marzo de 2015. Recuperado el 16 de diciembre de 2015, de $<$ https://cejil.org/comunicados/organizaciones-denunciaron-ante-cidh-violacion-de-derechos-humanos-porla-construccion-d>.
} 


\section{REFERENCIAS BIBLIOGRÁFICAS}

BERMANN, C., Brasil não precisa de Belo Monte, Amigos da Terra-Amazônia Brasileira, São Paulo, Brasil, 2002. Recuperado el 20 de febrero de 2015, de $<$ http://www.amazonia.org.br/opiniao/artigo_detail.cfm?id=14820>

BRYANT, R. y BAILEY, S., Third World Political Ecology, Routledge, Londres, 1997.

BUSINESS AND HUMAN RIGHTS RESOURCE CENTRE. Abusos de derechos humanos relacionados con el Mundial de la FIFA del 2014 y los Juegos Olímpicos del 2016 en Brasil. 2014. Recuperado el 16 de diciembre de 2015, de <http://businesshumanrights.org/es/abusos-de-derechos-humanos-relacionados-al-mundial-de-la-fifa-del2014-y-los-juegos-ol\%C3\%ADmpicos-del-2016-en-brasil>.

CARVALHO, A. S. C. et ál., "Levels of $\mathrm{As}, \mathrm{Cd}, \mathrm{Pb}$ and $\mathrm{Hg}$ found in the hair from people living in Altamira, Pará, Brazil: environmental implications in the Belo Monte area", $J$. Braz. Chem. Soc., 2009, vol. 20, núm. 6,

CASTRO, F. y FUTEMMA, C. (org.), Governança Ambiental no Brasil - entre o socioambientalismo e a economia verde, Editorial Paco, São Paulo, 2015

CENTRO POR LA JUSTICIA Y EL DERECHO INTERNACIONAL (CEJIL). Organizaciones denunciaron ante CIDH violación de derechos humanos por la construcción del canal en Nicaragua. Washington, D.C., 17 de marzo de 2015. Recuperado el 16 de diciembre de 2015, de $<$ https://cejil.org/comunicados/organizaciones-denunciaron-ante-cidh-violacion-dederechos-humanos-por-la-construccion-d $>$.

COLCHESTER, M., Dams, Indigenous People and vulnerable ethnic minorities, Forest Peoples Programme, Sudáfrica, 2000.

COMISIÓN INTERAMERICANA DE DERECHOS HUMANOS (CIDH). Caso Yanomami, Resolución núm. 12/85, caso núm. 7615 (Brasil), 5 de marzo de 1985. Recuperado el 16 de diciembre de 2015, de $<$ http://www.cidh.oas.org/annualrep/84.85sp/Brasil7615.htm>.

- Informe núm. 99/99. Caso 11.140. Mary y Carrie Dann. Estados Unidos. 27 de septiembre de 1999. Recuperado el 16 de diciembre de 2015, de 
$<$ http://www.cidh.oas.org/Indigenas/JURISPRUDENCIA/CASOSCIDH/17.CASO.11140 .EEUU.ADM.doc $>$.

- Informe núm. 40/04. Caso 12.053. Fondo. Comunidades indígenas mayas del distrito de Toledo. Belice. 12 de octubre de 2004. Recuperado el 16 de diciembre de 2015, de <https://www.cidh.oas.org/annualrep/2004sp/Belize.12053.htm>.

- Informe núm. 69/11. Petición 10.949. Admisibilidad. Magda Mateo Bruno. Perú. 31 de marzo de 2011. Recuperado el 16 de diciembre de 2015, de $<$ http://www.oas.org/es/cidh/decisiones/2011/PEAD10949ES.doc>.

- Informe núm. 88/03. Petición 11.533. Inadmisibilidad. Parque Natural Metropolitano. Panamá. 22 de octubre de 2003. Recuperado el 16 de diciembre de 2015, de $<$ http://www.cidh.oas.org/annualrep/2003eng/Panama.11533.htm>.

CORTE INTERAMERICANA DE DERECHOS HUMANOS (Corte IDH). Pueblo indígena Kichwa de Sarayaku contra Ecuador. Sentencia de 27 de junio de 2012. Fondo y reparaciones. Serie C núm. 245. Recuperado el 16 de diciembre de 2015, de $<$ http://corteidh.or.cr/docs/casos/articulos/seriec_245_esp.pdf $>$.

Caso Norín Catrimán y otros (dirigentes, miembros y activistas del pueblo indígena mapuche) contra Chile. Sentencia de 29 de mayo de 2014. Fondo, reparaciones y costas. Serie C núm. 279. Recuperado el 16 de diciembre de 2015, de $<$ http://www.corteidh.or.cr/docs/casos/articulos/seriec_279_esp.pdf $>$.

- Caso de la comunidad Mayagna (Sumo) Awas Tingni contra Nicaragua. Sentencia de 1 de febrero de 2000 (Excepciones Preliminares). Serie C núm. 66. Recuperado el 16 de diciembre de 2015, de $<$ http://www.corteidh.or.cr/docs/casos/articulos/Seriec_66_esp.pdf >.

CUNHA DE ANDRADE, D. y FERREIRA VALLE, L., "Impacts of the Belo Monte hydroelectric dam construction on pioneer vegetation formations along the Xingú River, Pará State, Brazil”, Braz. J. Bot., 2012, vol. 35, núm. 2.

DESGAGNE, R., Integrating environmental values into the European Convention on Human Rights, American Journal of International Law, 1995.

DOBSON, A, Justice and the environment - conceptions of environmental sustainability 
and dimensions of social justice, Oxford University Press, 1998.

DOUROJEANNI, M. J., "Human Impact on Protected Areas of the Peruvian Amazon", Wuerthner, G., Crist, E. y Butler, T. (eds.), Protecting the Wild: Parks and Wilderness, the Foundation for Conservation, Island Press-Center for Resource Economics, Washington D.C., Estados Unidos de América, 2015.

FAINGUELERNT, M., "Belo Monte. Reflexiones críticas sobre la trayectoria histórica del proyecto de la hidroeléctrica y los escollos de las licencias ambientales en el Brasil", Revista Contrapunto. Bienes comunes. Saqueo y resistencias, Universidad de la República, Montevideo, junio de 2013, p. 42.

FLEURY, L. C. y ALMEIDA, J., “A construção da Usina Hidrelétrica de Belo Monte: conflito ambiental e o dilema do desenvolvimento", Ambient. Soc., diciembre de 2013, vol. 16 , núm. 4.

FRANCO, F.C.O. y FEITOSA, M. L. A., "Desenvolvimento e direitos humanos: marcas de inconstitucionalidade no processo Belo Monte", Rev. direito GV, junio de 2013, vol. 9, núm. 1.

FURTADO, C., O mito do desenvolvimento econômico, Paz e Terra, Río de Janeiro, 1974.

GARCÍA RAMÍREZ, S. y CASTAÑEDA HERNÁNDEZ, M. (coord.), Recepción nacional del derecho internacional de los derechos humanos y admisión de la competencia contenciosa de la Corte Interamericana, Universidad Nacional Autónoma de México, México, 2009.

GUIMARÃES, R. P., "A ética da sustentabilidade e a formulação de políticas de desenvolvimento", Diniz et ál. (orgs.), O desafio da sustentabilidade: um debate socioambiental no Brasil, Editora Fundação Perseu Abramo, São Paulo, 2001.

ISA - Instituto Socioambiental, Especial Belo Monte. A polemica da usina de Belo Monte. Recuperado el 6 de febrero de 2016, de http://www.socioambiental.org/esp/bm/index.asp

MARÉS, C.F., "Introdução ao Direito Socioambiental", Lima, André, O Direito para o Brasil Socioambiental, Editora SafE, 2002. 
- A função social da terra, Sergio Antonio Fabris Editor, Porto Alegre, 2003.

MAZZUOLI, V. d. O y TEIXEIRA, G. d. F. M., "O direito internacional do meio ambiente e o greening da Convenção Americana sobre Direitos Humanos", Revista de direito GV, São Paulo 9(1), junio de 2013.

MCCULLY, P., Silenced Rivers: the ecology and politics of large dams, Zed Books, Londres, Reino Unido, 2001.

MURPHY, S. D., "Does the world need a new international environmental court", Geo. Wash. J. Int'l L. \& Econ., v. 32, 1999.

ORGANIZACIÓN DE LAS NACIONES UNIDAS (ONU). Declaración de Estocolmo. A/RES/2994(XXVII). Aprobada en sesión plenaria núm. 2112, de 15 de diciembre de 1972. Disponible en: $<$ http://www.unep.org/Documents.Multilingual/Default.asp?documentid=97\&articleid=1 503>. Fecha de consulta: 29 de febrero de 2015.

PINHEIRO, M. F. B., Problemas sociais e institucionais na implantação de hidrelétricas: seleção de casos recentes no Brasil e casos relevantes em outros países, Campinas, SP: [s.n.], 2007 [Dissertacao de Mestrado. Programa de Pós-Graduaçao em Engenharia Mecanica. UNICAMP. Brasil].

PINTO, L.F., "De Tucuruí a Belo Monte: a história avança mesmo?", Bol. Mus. Para. Emílio Goeldi. Ciênc. hum., diciembre de 2012, vol. 7, núm. 3, p. 777-782.

PROGRAMA DE LAS NACIONES UNIDAS PARA EL DESARROLLO (PNUD). Índices. Desenvolvimento Humano e IDH. Disponible en: http://www.pnud.org.br/IDH/DH.aspx. Fecha de consulta: 15 de noviembre de 2014. ROSA, L. P. et ál., "Are hydroelectric dams in the Brazilian Amazon significant sources of 'greenhouse' gases?', Environmental Conservation, Cambridge, v. 23, núm. 2, 1996.

SALLES CAVEDON-CAPDEVILLE, F. d., "L'écologisation du Système Interaméricain des Droits de l'Homme (SIDH): commentaire de la jurisprudence récente (2010-2013)", Revue juridique de l'environnement, vol. 39, núm. 3, 2014.

SANTILLI, J., Socioambientalismo e novos direitos: proteção jurídica à diversidade biológica e cultural, Ed. Peirópolis, 2005. 
SANTOS, L. A. O. y ANDRADE, L. M. M. de, As hidrelétricas do Xingú e os povos indígenas, Comissão Pro-Índio de São Paulo, São Paulo, 1988.

SILVA, E., "Transformações sócio-ambientais e a problemática ambiental no Brasil: o caso das hidrelétricas", Caminhos da Geografia (UFU. Online), 2007, v. 8, núm. 23.

TEIXEIRA, G., O greening no sistema interamericano de direitos humanos, Curitiba, Juruá, 2011.",

TRIBUNAL REGIONAL FEDERAL DA LA REGIÃO DE BRASIL. Apelação Cível no. 968.19.2011.4.01.3900/PA, 25/10/2013.

- Embargos de Declaração na Apelação Cível no. 2006.39.0300.0711-8/PA, 27/08/2012.

VENTURA, D. y CETRA ORTIZ, R., "O Brasil e o sistema interamericano de direitos humanos: de Maria da Penha a Belo Monte", Silva Filho, J.C. y Torelly, M. (orgs.), Justiça de Transição nas Américas: olhares interdisciplinares, fundamentos e padrões de efetivação, Forum, Belo Horizonte, 2013, p. 3. Documento de difusión gratuita. Recuperado el 16 de diciembre de 2015, de <http://www.conectas.org/arquivossite/Ventura\%20Cetra\%20O\%20Brasil\%20e\%20o\%20SIDH\%202012\%20(2)(1).pdf . 